\title{
Insurance status predicts acuity of thoracic aortic operations
}

\author{
Nicholas D. Andersen, MD, ${ }^{a}$ Jennifer M. Hanna, MD, MBA, ${ }^{a}$ Asvin M. Ganapathi, MD, ${ }^{a}$ \\ Syamal D. Bhattacharya, MD, ${ }^{\mathrm{a}}$ Judson B. Williams, MD, MHS, ${ }^{\mathrm{a}}$ Jeffrey G. Gaca, MD, ${ }^{\text {, }}$ \\ Richard L. McCann, MD, ${ }^{b}$ and G. Chad Hughes, MD
}

\begin{abstract}
Objective: Nonelective case status is the strongest predictor of mortality for thoracic aortic operations. We hypothesized that underinsured patients were more likely to require nonelective thoracic aortic surgery because of reduced access to preventative cardiovascular care and elective surgical services.
\end{abstract}

\begin{abstract}
Methods: Between June 2005 and August 2011, 826 patients were admitted to a single aortic referral center and underwent 1 or more thoracic aortic operations. Patients with private insurance or Medicare (insured group, $\mathrm{n}=736 ; 89 \%$ ) were compared with those with Medicaid or no insurance (underinsured group, $\mathrm{n}=90 ; 11 \%$ ).
\end{abstract}

\begin{abstract}
Results: The proportion of patients requiring nonelective surgery was higher for underinsured than insured patients $(56 \%$ vs $26 \%, P<.0001)$. Multivariable analysis revealed underinsurance to be the strongest independent predictor of nonelective case status (odds ratio [OR], 2.67; $P<.0001$ ). Preoperative use of lipid-lowering medications (OR, $0.63 ; P<.009)$ or a history of aortic surgery $(\mathrm{OR}, 0.48 ; P<.001)$ was associated with a decreased risk of nonelective operation. However, after adjustment for differences in preoperative characteristics and case status, underinsurance did not confer an increased risk of procedural morbidity or mortality (adjusted OR, $0.94 ; P=.83$ ) or late death (adjusted hazard ratio, $0.83, P=.58$ ) when compared with insured patients.

Conclusions: Underinsured patients were at the greatest risk of requiring nonelective thoracic aortic operation, possibly because of decreased use of lipid-lowering therapies and aortic surveillance. These data imply that greater access to preventative cardiovascular care may reduce the need for nonelective thoracic aortic surgery and lead to improved survival from thoracic aortic disease. (J Thorac Cardiovasc Surg 2014;148:2082-6)
\end{abstract}

Surgical repair of the thoracic aorta is increasing in frequency and represents one of the most formidable challenges in cardiovascular medicine.$^{1-3}$ Prophylactic replacement of diseased aortic segments in the elective surgical setting is typically associated with operative mortality rates less than $5 \%$ in contemporary reports. ${ }^{1,3}$ However, $40 \%$ of operations are performed on an urgent or emergency basis as the result of acute aortic catastrophes, such as aneurysm rupture or aortic dissection, for which operative mortality rates can reach $50 \% .^{3-5}$ Correspondingly, a recent report from the Society of Thoracic Surgeons found that patients undergoing nonelective operation were at the greatest risk of major morbidity and mortality after proximal thoracic

From the Divisions of Cardiovascular and Thoracic Surgery ${ }^{\mathrm{a}}$ and Vascular Surgery, ${ }^{\mathrm{b}}$ Department of Surgery, Duke University Medical Center, Durham, NC.

Funded by the Thoracic Surgery Foundation for Research and Education (Chicago, Ill) Research Fellowship (to N.D.A.) and National Institutes of Health (Bethesda, Md) Grants T32-CA093245 (to S.D.B.), T32-HL069749 (to J.B.W.), and U01-HL088953 (to J.B.W.).

Disclosures: Authors have nothing to disclose with regard to commercial support.

Read at the American College of Surgeons 98th Annual Clinical Congress, 67th Annual Surgical Forum Program, September 30 to October 4, 2012, Chicago, Illinois.

Received for publication Dec 4, 2013; revisions received Feb 24, 2014; accepted for publication March 12, 2014; available ahead of print April 9, 2014.

Address for reprints: G. Chad Hughes, MD, Center for Aortic Disease, Division of Cardiovascular and Thoracic Surgery, Duke University Medical Center, Box 3051, Durham, NC 27710 (E-mail: gchad.hughes@duke.edu).

$0022-5223 / \$ 36.00$

Copyright (c) 2014 by The American Association for Thoracic Surgery

http://dx.doi.org/10.1016/j.jtcvs.2014.03.013 aortic replacement. ${ }^{3}$ These data suggest the single most important method of improving the surgical outcomes of patients with thoracic aortic disease may be reducing the incidence of acute aortic events requiring expedited repair. Efforts to identify and target patients at high-risk of requiring nonelective thoracic aortic surgery are therefore warranted.

Prior studies have demonstrated that lack of health insurance was the strongest predictor of need for emergency operation for ruptured abdominal aortic aneurysm. ${ }^{6,7}$ Individuals without health insurance may be at higher risk of aortic instability because of decreased use of cardiovascular preventative care services, such as antihypertensive and lipid-lowering therapies, smokingcessation programs, and aortic surveillance, or they may lack access to elective surgical care. We therefore hypothesized that patients with inadequate health insurance were more likely to require nonelective thoracic aortic operation and experience worse outcomes.

\section{METHODS}

\section{Patient Population and Data Collection}

This study was approved by the institutional review board of Duke University, and the need for individual patient consent was waived. A query of the Duke Thoracic Aortic Surgery Database ${ }^{8-11}$ was performed to identify all patients who underwent 1 or more thoracic aortic operations (open, endovascular, or hybrid operations involving the proximal aorta, arch, descending, or thoracoabdominal aorta) between June 2005 and August 2011. Patients undergoing surgery for acute traumatic aortic transection were excluded $(\mathrm{n}=18)$ because these procedures are uniformly 


\section{Abbreviation and Acronym}

$\mathrm{OR}=$ odds ratio

performed nonelectively. Institutional billing databases were then queried to determine each patient's insurance status (private insurance, Medicare, Medicaid, or no insurance) at the time of hospital admission. Operations were performed as previously described. ${ }^{8-11}$

\section{Variable Definitions}

Medicare is a national health insurance program administered by the US federal government that provides health insurance for people aged 65 years or more, people aged less than 65 years with certain disabilities, and people of all ages with end-stage renal disease requiring dialysis or a kidney transplant. Medicaid is jointly funded by state and federal governments and is a health insurance program that provides health insurance for lower-income people, families and children, the elderly, and people with disabilities. ${ }^{12}$ Medicaid reimburses practitioners at lower rates than other forms of insurance, and patients with Medicaid are generally considered underinsured. ${ }^{13-15}$

Comorbid conditions and postoperative complications were defined using Society of Thoracic Surgeons definitions (www.sts.org). Nonelective procedure status was defined as patients undergoing urgent or emergency operation. Operative mortality was defined as death from any cause in-hospital or within 30 days of the index procedure. Major morbidity or mortality was defined as the composite of prolonged ventilation, myocardial infarction, acute renal failure, permanent paraparesis/paraplegia, stroke, or death. Long-term survival was assessed from the medical record and a query of the Social Security death database.

\section{Statistical Analysis}

Patients were stratified into 2 insurance status groups (insured or underinsured) for statistical comparisons. Patients with private insurance or Medicare at the time of admission were classified as "insured," and those with Medicaid or no insurance were classified as "underinsured." Continuous and categoric variables were compared between insured and underinsured patients using the Mann-Whitney rank sum test or chi-square test, respectively. Predictors of nonelective procedure status were identified using multivariable logistic regression analysis. All preoperative patient characteristics (Table 1) with univariate association $(P<.05)$ to nonelective procedure status were included and retained in the final model. The risk-adjusted association between insurance status and outcomes was performed using logistic regression or Cox proportional-hazards regression models to adjust for differences in patient demographics and procedure status between insurance groups. In both models, odds ratios and hazard ratios were adjusted for all variables with $P$ value less than .05 on univariate analysis (age, race, hyperlipidemia, coronary artery disease, chronic obstructive pulmonary disease, peripheral vascular disease, and case status). Calculations were performed using STATA 11.1 (StataCorp LP, College Station, Tex).

\section{RESULTS \\ Patient Characteristics}

Between June 2005 and August 2011, 826 patients were admitted to a single aortic referral center and underwent 1 or more thoracic aortic operations. Of these, $736(89 \%)$ had private insurance $(\mathrm{n}=325 ; 39 \%)$ or Medicare $(\mathrm{n}=411 ; 50 \%)$ and were classified as insured. The remaining 90 patients $(11 \%)$ had Medicaid $(\mathrm{n}=38 ; 5 \%)$ or no insurance $(n=52 ; 6 \%)$ and were classified as underinsured. A comparison of baseline patient characteristics between insured and underinsured patients is shown in Table 1 . Underinsured patients were noted to be younger by an average of 14 years, and more were of minority race. Underinsured patients also were observed to harbor fewer comorbid diagnoses than insured patients and had lower documented rates of hyperlipidemia, coronary artery disease, chronic obstructive pulmonary disease, and peripheral vascular disease at the time of hospital admission.

\section{Clinical Presentations, Operations, and Procedural Outcomes}

The comparisons of operative parameters and procedural outcomes between insured and underinsured patients are shown in Tables 2 and 3, respectively. The number of aortic emergencies were higher in the underinsured group, and $56 \%$ of underinsured patients underwent urgent or emergency operation compared with $26 \%$ of insured patients. However, the indications for surgery and the case mix appeared similar between groups, and there were no major differences in the redo status, extent of aortic replacement, concomitant procedures, use of endovascular therapies, use of circulatory arrest, or operative times between insured and underinsured patients. In addition, unadjusted measures of procedural morbidity and mortality were comparable between groups, and no major differences in length of stay or rates of dialysis, paraplegia, stroke, or death were observed.

\section{Predictors of Nonelective Procedure Status}

A multivariable analysis was performed to determine the preoperative patient factors that were independently associated with the need for nonelective operation (Table 4). Preoperative variables with univariate association with nonelective case status were younger age $(P=.007)$, nonwhite race $(P<.0001)$, absence of hyperlipidemia $(P<.0001)$, renal insufficiency $(P=.001)$, absence of peripheral vascular disease $(P=.01)$, underinsured insurance status $(P<.0001)$, and no history of aortic surgery $(P<.0001)$. On multivariable analysis, underinsured insurance status, minority race, and renal insufficiency were associated with the need for nonelective operation. In contrast, patients with a preoperative diagnosis of hyperlipidemia (defined as lipid-lowering medication use at the time of admission) or a history of aortic surgery were less likely to require nonelective operation.

\section{Association Between Insurance Status and Outcomes}

The unadjusted and adjusted associations between insurance status and operative mortality, major morbidity and mortality, and late death were assessed to determine the independent effect of insurance status on patient outcomes. After adjustment for preoperative patient characteristics, 
TABLE 1. Baseline characteristics

\begin{tabular}{lccc}
\hline \multicolumn{1}{c}{ Variable } & $\begin{array}{c}\text { Insured } \\
(\mathbf{n}=\mathbf{7 3 6})\end{array}$ & $\begin{array}{c}\text { Underinsured } \\
(\mathbf{n}=\mathbf{9 0})\end{array}$ & $\boldsymbol{P}$ value \\
\hline Age $(\mathrm{y})$ & $61.6(14.3)$ & $47.2(11.7)$ & .0001 \\
Male & $474(64 \%)$ & $60(67 \%)$ & .67 \\
White race & $554(75 \%)$ & $35(39 \%)$ & .0001 \\
Body mass index $\left(\mathrm{kg} / \mathrm{m}^{2}\right)$ & $27.8(5.7)$ & $29.1(6.7)$ & .08 \\
Hypertension & $615(84 \%)$ & $73(81 \%)$ & .56 \\
Hyperlipidemia & $409(56 \%)$ & $29(32 \%)$ & .0001 \\
Active or recent tobacco use & $397(54 \%)$ & $57(63 \%)$ & .09 \\
Diabetes & $80(11 \%)$ & $7(8 \%)$ & .37 \\
Coronary artery disease & $208(28 \%)$ & $13(14 \%)$ & .005 \\
History of stroke & $79(11 \%)$ & $6(7 \%)$ & .23 \\
Chronic obstructive pulmonary & $154(21 \%)$ & $10(11 \%)$ & .03 \\
$\quad$ disease & & & \\
Baseline creatinine $>1.5 \mathrm{mg} / \mathrm{dL}$ & $136(18 \%)$ & $18(20 \%)$ & .73 \\
Peripheral vascular disease & $131(18 \%)$ & $1(1 \%)$ & .0001 \\
Connective tissue disease & $46(6 \%)$ & $8(9 \%)$ & .34 \\
Previous aortic surgery & $256(35 \%)$ & $27(30 \%)$ & .37 \\
\hline
\end{tabular}

Data are represented as mean (standard deviation) or number (percent).

comorbidities, and case status, insurance status was not associated with an increased risk of operative mortality or major morbidity (Table 5). Unadjusted survival analysis revealed improved long-term survival for underinsured patients (5-year survival $86.7 \%$ vs $76.3 \% ; P=.02$ ), possibly as a result of the significant age difference between the groups. However, after adjustment for age and other confounders, insurance status was not associated with late death (Table 5).

\section{DISCUSSION}

The present study assessed the association between insurance status and the presentation and outcomes of thoracic aortic operations, on the basis of the hypothesis that patients with inadequate health insurance are at a higher-risk of developing acute aortic events requiring expedited surgery because of decreased use of preventative health care resources or other barriers to elective surgical care. The primary study finding was that underinsured patients were at a significantly increased risk of requiring nonelective thoracic aortic operation when compared with insured patients. However, after presentation for treatment, insurance status did not confer additional independent operative risk.

The mechanism by which insurance status may affect the acuity of thoracic aortic disease at presentation is not addressed by the present analysis. However, multiple lines of evidence suggest inadequate health insurance leads to more severe cardiovascular disease because of decreased use of preventative care resources. Prior studies have shown that the underinsured are less likely to undergo screening for hypertension or hypercholesterolemia, ${ }^{16}$ have higher rates of undiagnosed hypertension and hypercholesterolemia, ${ }^{17}$ are less likely to be taking any antihypertensive or
TABLE 2. Operative parameters

\begin{tabular}{|c|c|c|c|}
\hline Variable & $\begin{array}{c}\text { Insured } \\
(\mathbf{n}=736)\end{array}$ & $\begin{array}{c}\text { Underinsured } \\
(\mathbf{n}=\mathbf{9 0})\end{array}$ & $\begin{array}{c}P \\
\text { value } \\
\end{array}$ \\
\hline Nonelective case status & $190(26 \%)$ & $50(56 \%)$ & .0001 \\
\hline Nonelective indication & & & .87 \\
\hline Aortic dissection & $94(49 \%)$ & $28(56 \%)$ & \\
\hline $\begin{array}{l}\text { Symptomatic aneurysm/ } \\
\text { impending rupture }\end{array}$ & $49(26 \%)$ & $11(22 \%)$ & \\
\hline $\begin{array}{l}\text { Severe aortic insufficiency } \\
\text { or stenosis }\end{array}$ & $19(10 \%)$ & $6(12 \%)$ & \\
\hline Ruptured aneurysm & $12(6 \%)$ & $1(2 \%)$ & \\
\hline Endocarditis & $8(4 \%)$ & $2(4 \%)$ & \\
\hline Type I or III endoleak & $3(2 \%)$ & $1(2 \%)$ & \\
\hline Unstable angina & $2(1 \%)$ & $1(2 \%)$ & \\
\hline $\begin{array}{l}\text { Other nonelective concomitant } \\
\text { procedure }\end{array}$ & $3(2 \%)$ & 0 & \\
\hline \multicolumn{4}{|l|}{ Maximum aortic diameter, $\mathrm{cm}$} \\
\hline $\begin{array}{l}\text { Patients with acute dissection } \\
\qquad(\mathrm{n}=89, \mathrm{n}=25)\end{array}$ & $5.3(1.1)$ & $4.9(0.8)$ & .13 \\
\hline $\begin{array}{l}\text { All other patients } \\
\qquad(\mathrm{n}=602, \mathrm{n}=58)\end{array}$ & $5.9(1.3)$ & $6.0(1.7)$ & .69 \\
\hline \multicolumn{4}{|l|}{ Segments of aorta repaired } \\
\hline Root & $168(23 \%)$ & $26(29 \%)$ & .20 \\
\hline Ascending aorta & $229(31 \%)$ & $26(29 \%)$ & .66 \\
\hline Arch & $378(51 \%)$ & $46(51 \%)$ & .97 \\
\hline Descending aorta & $212(29 \%)$ & $28(31 \%)$ & .65 \\
\hline Thoracoabdominal aorta & $85(12 \%)$ & $8(9 \%)$ & .45 \\
\hline Redo sternotomy & $106(14 \%)$ & $13(14 \%)$ & .99 \\
\hline Concomitant procedure & $206(28 \%)$ & $27(30 \%)$ & .69 \\
\hline $\begin{array}{l}\text { Use of thoracic endovascular } \\
\text { aortic repair }\end{array}$ & $251(34 \%)$ & $29(32 \%)$ & .72 \\
\hline Use of circulatory arrest & $349(47 \%)$ & $45(50 \%)$ & .64 \\
\hline $\begin{array}{l}\text { Crossclamp time } \\
\qquad(\mathrm{n}=409, \mathrm{n}=54)\end{array}$ & $138.4(47.2)$ & $130.9(45.7)$ & .25 \\
\hline Cardiopulmonary bypass time & $214.4(56.7)$ & $218.9(71.9)$ & .93 \\
\hline
\end{tabular}

$(\mathrm{n}=443, \mathrm{n}=59)$

Data are represented as mean (standard deviation) or number (percent).

lipid-lowering medications, ${ }^{18}$ have inadequate blood pressure and cholesterol control among those who are taking medications, ${ }^{19,20}$ and have higher rates of tobacco use than individuals with health insurance. ${ }^{16,21}$ Given that hypertension, hyperlipidemia, and smoking are the most significant modifiable risk factors for the development and progression of thoracic aortic disease, ${ }^{22-26}$ these factors likely contribute to the high incidence of acute aortic events in the underinsured. In the present study, patients with hyperlipidemia were defined as those who were taking lipid-lowering medications at the time of admission. The finding that patients undergoing treatment for hyperlipidemia were less likely to require nonelective surgery lends further support to the hypothesis that preventative cardiovascular care and risk factor modification reduce the frequency of aortic emergencies and suggests that the low rate of comorbid diagnoses among the underinsured was likely due in part to underdiagnosis. 
TABLE 3. Thirty-day/in-hospital adverse events

\begin{tabular}{lccc}
\hline \multicolumn{1}{c}{ Variable } & $\begin{array}{c}\text { Insured } \\
(\mathbf{n = 7 3 6 )}\end{array}$ & $\begin{array}{c}\text { Underinsured } \\
(\mathbf{n = 9 0 )}\end{array}$ & $\boldsymbol{P}$ value \\
\hline Prolonged ventilation $(>24 \mathrm{~h})$ & $76(10 \%)$ & $12(13 \%)$ & .38 \\
Tracheostomy & $25(3 \%)$ & $1(1 \%)$ & .24 \\
Myocardial infarction & $10(1 \%)$ & 0 & .27 \\
Acute renal failure (creatinine & $80(11 \%)$ & $8(9 \%)$ & .57 \\
$\quad>2.0 \mathrm{mg} / \mathrm{dL}$ and $>2 \times$ baseline) & & & \\
New-onset dialysis & $26(4 \%)$ & $2(2 \%)$ & .52 \\
Permanent paraparesis/paraplegia & $13(2 \%)$ & $1(1 \%)$ & .65 \\
Stroke (neurologic deficit & $26(4 \%)$ & $3(3 \%)$ & .92 \\
$\quad$ lasting >72 h) & & & \\
Postoperative length of stay (d) & $8.4(9.0)$ & $6.8(7.7)$ & .05 \\
30-d/in-hospital death & $43(6 \%)$ & $4(4 \%)$ & .59 \\
Major morbidity or mortality & $159(22 \%)$ & $18(20 \%)$ & .73 \\
\hline
\end{tabular}

Data are represented as mean (standard deviation) or number (percent).

Other explanations for the increased need for nonelective thoracic aortic surgery by underinsured patients may include delayed access to elective surgical services because of financial barriers, difficulties navigating the health care system, or withholding of costly prophylactic operations from asymptomatic individuals who do not have a means to pay. In support of the latter, studies have shown that uninsured patients receive fewer hospital resources and are less likely to undergo major cardiovascular therapeutic procedures, including cardiac catheterization and coronary artery bypass grafting, even after hospital admission for heart attack. ${ }^{18}$ However, individual review of patient charts revealed that no underinsured patients who underwent nonelective operation in our study had previously been referred for surgery at our institution, suggesting that this mechanism was not a significant contributor in our series. Alternatively, uninsured patients are known to receive fewer screening and diagnostic tests than insured patients, ${ }^{18}$ which may lead to decreased identification of occult aortic pathologies. Correspondingly, the finding of a reduced need for nonelective operation in patients with a history of aortic surgery may be due to increased use of aortic surveillance imaging in this population. Together, these data suggest that policy changes aimed at reducing the number of underinsured/uninsured patients in the United States may decrease the number of acute thoracic aortic events

TABLE 4. Independent predictors of nonelective operation

\begin{tabular}{lcc}
\hline \multicolumn{1}{c}{ Variable } & OR $(\mathbf{9 5} \% \mathbf{C I})$ & $\boldsymbol{P}$ value \\
\hline Underinsured & $2.67(1.61-4.41)$ & $<.0001$ \\
Nonwhite race & $2.25(1.58-3.19)$ & $<.0001$ \\
Baseline creatinine $>1.5 \mathrm{mg} / \mathrm{dL}$ & $1.75(1.17-2.63)$ & .007 \\
Age $(\mathrm{y})$ & $1.00(0.99-1.02)$ & .55 \\
Peripheral vascular disease & $0.94(0.56-1.58)$ & .83 \\
Hyperlipidemia & $0.63(0.45-0.89)$ & .009 \\
Prior aortic surgery & $0.48(0.33-0.70)$ & $<.0001$ \\
\hline
\end{tabular}

$C I$, Confidence interval; $O R$, odds ratio.
TABLE 5. Association between insurance status and operative mortality, major morbidity and mortality, and late death for patients undergoing thoracic aortic operation

\begin{tabular}{lcc}
\hline Underinsured vs insured (referent) & OR/HR (95\% CI) & $\boldsymbol{P}$ value \\
\hline Operative mortality & & \\
$\quad$ Crude & $0.75(0.26-2.14)$ & .59 \\
$\quad$ Adjusted & $0.97(0.30-3.12)$ & .96 \\
Major morbidity and mortality & & \\
$\quad$ Crude & $0.91(0.53-1.57)$ & .73 \\
$\quad$ Adjusted & $0.94(0.51-1.73)$ & .83 \\
Late death & & \\
$\quad$ Crude & $0.49(0.27-0.91)$ & .02 \\
$\quad$ Adjusted & $0.83(0.43-1.61)$ & .58 \\
\hline CI, Confidence interval; $H R$, hazard ratio; $O R$, odds ratio.
\end{tabular}

requiring surgery and limit mortality from this disease process.

Prior studies by LaPar and colleagues ${ }^{14,15}$ reported that Medicaid and uninsured payer status confer increased risk-adjusted in-hospital mortality for heart valve and coronary artery bypass graft operations. The explanation for this disparity is unknown but may again relate to decreased postoperative resource use for patients with lesser forms of health insurance or referral to less-experienced surgeons. ${ }^{13}$ However, after adjustment for baseline differences between patients and case status, the present study found no association between insurance status and patient outcomes. The difference between our study and the findings of LaPar and colleagues ${ }^{14,15}$ may be due to the single-institution design and unique differences in locoregional or hospital practices that relate to insurance status. For instance, all patients requiring thoracic aortic surgery at our hospital undergo operation by the same team of highly experienced surgeons regardless of insurance status, ${ }^{27}$ which may contribute to the normalization of operative parameters and outcomes between insured and underinsured patients in our study.

\section{Study Limitations}

The present study contains several important limitations: (1) The study only includes patients who underwent operation and therefore excludes patients who died of thoracic aortic disease before hospital presentation, were deferred operation because of prohibitive operative risk, or who received medical management for uncomplicated type $\mathrm{B}$ dissection. This may have led to an underestimate of the effect of insurance status on presentations and outcomes, given that underinsured patients are predicted to experience more acute aortic events. (2) The present study is a retrospective, observational analysis and may be limited by unmeasured confounders that are not accounted for in risk-adjustment models. (3) The relationship among health insurance, health use, and health is complex and highly influenced by other social variables, such as education level, 
employment, and socioeconomic status. For instance, the association between race and nonelective operation may be due to the confounding effect of socioeconomic status, a variable that was not controlled for in the present analysis. ${ }^{28}$ Thus, further study would be needed to reconcile the true effect of insurance status on the presentations and outcomes of thoracic aortic operations independently of these other considerations. (4) The present study represents a single-institution analysis, and the small sample size limits the number of insurance status groups that could be compared. In addition, regional differences in patient demographics, hospital practices, and insurance patterns may limit the generalizability of our results to other settings.

\section{CONCLUSIONS}

The present study found that underinsured patients were at the greatest risk of requiring nonelective thoracic aortic operations, possibly because of decreased use of lipidlowering therapies and aortic surveillance. However, after presentation for treatment, insurance status did not confer additional independent operative risk. These data imply that greater access to preventative cardiovascular care may reduce the need for nonelective thoracic aortic surgery and lead to improved survival from thoracic aortic disease. Additional multi-institutional studies are needed to validate these results.

\section{References}

1. Kouchoukos NT, Dougenis D. Surgery of the thoracic aorta. NEngl J Med. 1997; 336:1876-88.

2. Clouse WD, Hallett JW Jr, Schaff HV, Gayari MM, Ilstrup DM, Melton LJ 3rd. Improved prognosis of thoracic aortic aneurysms: a population-based study. JAMA. 1998;280:1926-9.

3. Williams JB, Peterson ED, Zhao Y, O'Brien SM, Andersen ND, Miller DC, et al. Contemporary results for proximal aortic replacement in North America. J Am Coll Cardiol. 2012;60:1156-62.

4. Hagan PG, Nienaber CA, Isselbacher EM, Bruckman D, Karavite DJ, Russman PL, et al. The International Registry of Acute Aortic Dissection (IRAD): new insights into an old disease. JAMA. 2000;283:897-903.

5. Rigberg DA, McGory ML, Zingmond DS, Maggard MA, Agustin M, Lawrence PF, et al. Thirty-day mortality statistics underestimate the risk of repair of thoracoabdominal aortic aneurysms: a statewide experience. J Vasc Surg. 2006;43:217-23.

6. Boxer LK, Dimick JB, Wainess RM, Cowan JA, Henke PK, Stanley JC, et al. Payer status is related to differences in access and outcomes of abdominal aortic aneurysm repair in the United States. Surgery. 2003;134:142-5.

7. Giacovelli JK, Egorova N, Nowygrod R, Gelijns A, Kent KC, Morrissey NJ. Insurance status predicts access to care and outcomes of vascular disease. J Vasc Surg. 2008;48:905-11.

8. Hughes GC, Lee SM, Daneshmand MA, Bhattacharya SD, Williams JB, Tucker SW Jr, et al. Endovascular repair of descending thoracic aneurysms: results with "on-label" application in the post Food and Drug Administration approval era. Ann Thorac Surg. 2010;90:83-9.
9. Lima B, Williams JB, Bhattacharya SD, Shah AA, Andersen N, Gaca JG, et al. Results of proximal arch replacement using deep hypothermia for circulatory arrest: is moderate hypothermia really justifiable? Am Surg. 2011;77:1438-44.

10. Hughes GC, Andersen ND, Hanna JM, McCann RL. Thoracoabdominal aortic aneurysm: hybrid repair outcomes. Ann Cardiothorac Surg. 2012;1:311-9.

11. Andersen ND, Williams JB, Hanna JM, Shah AA, McCann RL, Hughes GC Results with an algorithmic approach to hybrid repair of the aortic arch. J Vasc Surg. 2013;57:655-67.

12. Centers for Medicare \& Medicaid Services. Available at: http://www.cms.gov/. Accessed March 3, 2013.

13. LaPar DJ, Bhamidipati CM, Mery CM, Stukenborg GJ, Jones DR, Schirmer BD, et al. Primary payer status affects mortality for major surgical operations. Ann Surg. 2010;252:544-51.

14. Lapar DJ, Bhamidipati CM, Walters DM, Stukenborg GJ, Lau CL, Kron IL, et al. Primary payer status affects outcomes for cardiac valve operations. J Am Coll Surg. 2011;212:759-67.

15. LaPar DJ, Stukenborg GJ, Guyer RA, Stone ML, Bhamidipati CM, Lau CL, et al. Primary payer status is associated with mortality and resource utilization for coronary artery bypass grafting. Circulation. 2012;126(11 Suppl 1):S132-9.

16. Ayanian JZ, Weissman JS, Schneider EC, Ginsburg JA, Zaslavsky AM. Unmet health needs of uninsured adults in the United States. JAMA. 2000;284:2061-9.

17. Ayanian JZ, Zaslavsky AM, Weissman JS, Schneider EC, Ginsburg JA. Undiagnosed hypertension and hypercholesterolemia among uninsured and insured adults in the Third National Health and Nutrition Examination Survey. Am J Public Health. 2003;93:2051-4.

18. Hadley J. Sicker and poorer-the consequences of being uninsured: a review of the research on the relationship between health insurance, medical care use, health, work, and income. Med Care Res Rev. 2003;60(2 Suppl):3S-75S; discussion 6S-112S.

19. Moy E, Bartman BA, Weir MR. Access to hypertensive care. Effects of income, insurance, and source of care. Arch Intern Med. 1995;155:1497-502.

20. Gandelman G, Aronow WS, Varma R. Prevalence of adequate blood pressure control in self-pay or Medicare patients versus Medicaid or private insurance patients with systemic hypertension followed in a university cardiology or general medicine clinic. Am J Cardiol. 2004;94:815-6.

21. From the Centers for Disease Control and Prevention. Self-assessed health status and selected behavioral risk factors among persons with and without health-care coverage-United States, 1994-1995. JAMA. 1998;279:1063.

22. Hiratzka LF, Bakris GL, Beckman JA, Bersin RM, Carr VF, Casey DE Jr, et al. 2010 ACCF/AHA/AATS/ACR/ASA/SCA/SCAI/SIR/STS/SVM guidelines for the diagnosis and management of patients with Thoracic Aortic Disease: a report of the American College of Cardiology Foundation/American Heart Association Task Force on Practice Guidelines, American Association for Thoracic Surgery, American College of Radiology, American Stroke Association, Society of Cardiovascular Anesthesiologists, Society for Cardiovascular Angiography and Interventions, Society of Interventional Radiology, Society of Thoracic Surgeons, and Society for Vascular Medicine. Circulation. 2010;121:e266-369.

23. Dapunt OE, Galla JD, Sadeghi AM, Lansman SL, Mezrow CK, de Asla RA, et al. The natural history of thoracic aortic aneurysms. J Thorac Cardiovasc Surg. 1994; 107:1323-33.

24. Cronenwett JL, Murphy TF, Zelenock GB, Whitehouse WM Jr, Lindenauer SM, Graham LM, et al. Actuarial analysis of variables associated with rupture of small abdominal aortic aneurysms. Surgery. 1985;98:472-83.

25. Shores J, Berger KR, Murphy EA, Pyeritz RE. Progression of aortic dilatation and the benefit of long-term beta-adrenergic blockade in Marfan's syndrome. N Engl J Med. 1994;330:1335-41.

26. Stein LH, Berger J, Tranquilli M, Elefteraides JA. Effect of statin drugs on thoracic aortic aneurysms. Am J Cardiol. 2013;112:1240-5.

27. Andersen ND, Ganapathi AM, Hanna JM, Williams JB, Gaca JG, Hughes GC Outcomes of acute type A dissection repair before and after implementation of a multidisciplinary thoracic aortic surgery program. J Am Coll Cardiol December 20, 2013. [Epub ahead of print].

28. Bennett KM, Scarborough JE, Pappas TN, Kepler TB. Patient socioeconomic status is an independent predictor of operative mortality. Ann Surg. 2010;252:552-8. 